\title{
HARD-YET-TOUGH HIGH-VANADIUM HIGH-SPEED STEEL COMPOSITE COATING IN-SITU ALLOYED ON DUCTILE IRON BY ATMOSPHERIC PLASMA ARC
}

\author{
HUATANG $\mathrm{CAO}^{1}, \mathrm{XUANPU}^{\mathrm{DONG}}{ }^{2} \& \mathrm{YUTAO}^{\mathrm{PEI}}{ }^{1}$ \\ ${ }^{1}$ Department of Advanced Production Engineering, Engineering and Technology Institute Groningen, \\ University of Groningen, The Netherlands. \\ ${ }^{2}$ State Key Laboratory of Materials Processing and Die \& Mould Technology, School of Materials Science and \\ Engineering, Huazhong University of Science and Technology, Wuhan, China.
}

\begin{abstract}
A graded high-vanadium alloy composite coating was synthesized from premixed powders $(\mathrm{V}, \mathrm{Cr}$, $\mathrm{Ti}, \mathrm{Mo}, \mathrm{Nb}$ ) on ductile iron (DI) substrate via atmospheric plasma arc surface alloying process. The resulted cross-section microstructure is divided into three distinct zones: upper alloyed zone (AZ) rich with spherical primary carbides, middle melted zone (MZ) with fine white iron structure and lower heat affected zone (HAZ). Spherical or bulk-like primary carbides with diameter $<1 \mu \mathrm{m}$ in the $\mathrm{AZ}$ are formed via in-situ reactions between alloy powders and graphite in DI. Microstructural characterizations indicate that the carbides are primarily MC-type $(\mathrm{M}=\mathrm{V}, \mathrm{Ti}, \mathrm{Nb})$ carbides combined with mixed hardphases such as $\mathrm{M}_{2} \mathrm{C}, \mathrm{M}_{7} \mathrm{C}_{3}, \mathrm{M}_{23} \mathrm{C}_{6}$, and martensite. Disperse distribution of spherical, submicron-sized metal carbides in an austenite/ledeburite matrix render the graded coating hard-yet-tough. The maximum microhardness of the upper alloyed zone is $950 \mathrm{HV}_{0.2}$, which is five times that of the substrate. Significant plastic deformation with no cracking in the micro-indentations points to a high toughness. The graded high-vanadium alloy composite coating exhibits superior tribological performance in comparison to Mn13 steel and plasma transferred arc remelted DI.

Keywords: high-vanadium high-speed steel coating, mechanical properties, metal-based composites, plasma surface alloying
\end{abstract}

\section{INTRODUCTION}

Ductile iron (DI) is widely used in a broad range of industrial applications such as machine tool beds, dies, punches, cylinders, etc., owing to its low production cost combined with favorable properties like machinability, excellent castability and comprehensive strength-toughness [1-3]. However, in harsh service circumstances like those in mining and rolling sectors, the low hardness and poor wear resistance limit its further industrial applications.

High-speed steel (HSS) coating is a promising candidate for offering highly desired surface properties on a DI substrate considering that HSS contains a variety of primary alloy carbides rich in vanadium, chromium, tungsten and molybdenum, etc., which exhibits excellent comprehensive mechanical properties, highlighting its high resistance to wear, reliable toughness and hot hardness at elevated temperatures [4-8]. These superior mechanical properties are attributed to their microstructures consisting of fine, hard and stable carbides embedded in a strong and tough matrix. Among the carbides (e.g., $M C, M_{6} C, M_{7} C_{3}, M_{2} C$ ) in HSS, the cubic MC (e.g. VC) carbides are the most stable and hard and most frequently used as wear reliever (see Table 1).

HSS is usually fabricated by the powder metallurgy (PM) techniques, which enable the achievement of ultrafine and uniform carbide distributions. Thus, it renders possible substantial use of higher carbon and alloying element contents, which otherwise induce stress concentration and cracks when producing HSS in other conventional methods, for example ingot casting. On the other hand, PM processes are complicated and expensive. In the present 
Table 1. Hardness of the phases in high-speed steels and of DI [9].

\begin{tabular}{lllllll}
\hline Phase & DI & Martensite & $\gamma$-Fe & MC & $\mathrm{M}_{7} \mathrm{C}_{3}$ & $\mathrm{M}_{2} \mathrm{C}$ \\
\hline Hardness (HV) & 200 & $500-1010$ & 300 & $>2800$ & 1200 & 1500 \\
\hline
\end{tabular}

study, an atmospheric plasma transferred arc (PTA) was utilized to directly fabricate a high-vanadium high-speed steel (HVHSS)-graded layer on a DI substrate. Due to the rapid cooling and solidification rate and suitable alloy design, PTA achieves a HVHSS-white ironDI-graded structure that exhibits high hardness, high wear resistance and reliable toughness in an easy and economical way. The work has synthesized VC-dominated MC-type submicro carbides mixed with hard phases such as $\mathrm{M}_{2} \mathrm{C}, \mathrm{M}_{7} \mathrm{C}_{3}, \mathrm{M}_{23} \mathrm{C}_{6}$, and martensite in an austenite and or ledeburite matrix. The microstructure evolution, phase structure and structure-property relationship were studied in detail.

\section{EXPERIMENTAL ANALYSIS}

DI with a composition of Fe-3.7C-2.7Si-0.3Mn (wt.\%) was used as substrate for PTA treatment. The dimensions of the DI substrate were $100 \times 50 \times 20 \mathrm{~mm}$. The microstructure of the DI substrate consists of graphite nodules (diameter: $20-80 \mu \mathrm{m}$ ), embedded in pearlite regions and a ferrite matrix, see Fig. 1. The alloy powders were composed of ferrovanadium (FeV50), chromium, molybdenum, titanium and ferroniobium (FeNb60) with a composition of 10V-4Cr-3Ti-3Mo-2 $\mathrm{Nb}$ (weight ratio). Powders were mechanically blended and pre-coated onto polished DI substrate to form a layer of $\sim 25 \mu \mathrm{m}$ thickness. PTA process was performed by a home-made atmospheric plasma apparatus that has been detailed in elsewhere [3]. The plasma beam diameter, the current, the working distance, the scanning speed and overlapping rate were $4 \mathrm{~mm}, 100 \mathrm{~A}, 2 \mathrm{~mm}, 1.6 \mathrm{~m} \mathrm{~min}^{-1}$ and $25 \%$, respectively.

After PTA treatment, cross-sectional specimens were prepared by standard mechanical grinding and polishing. Microstructural characterizations were conducted using a scanning electron microscope (FEI XL30-FEG) equipped with energy-dispersive spectroscopy (EDS, EDAX). Transmission electron microscopy (TEM, JEOL 2010-FEG) was employed to identify MC structure and nanoscale elemental compositions (EDS, Bruker). Phase structures were identified by a X-ray diffractometer (XRD, Bruker D8 Advance) using $\mathrm{CuK} \alpha$ radiation. The microhardness across the depth was measured using a TMVS-1 Vickers microhardness

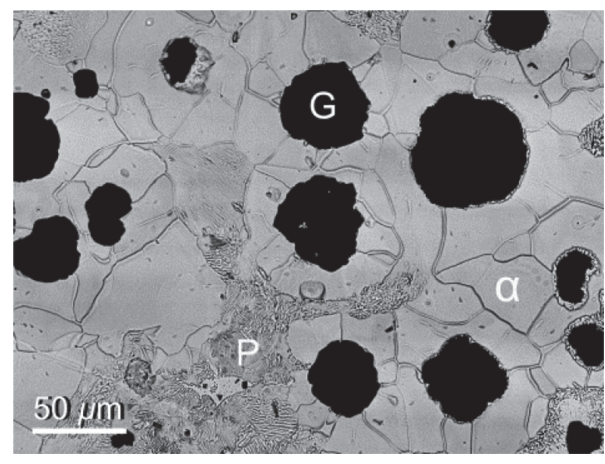

Figure 1: As-received ductile iron ( $\alpha$ : ferrite; G: graphite and P: pearlite). 
tester with a load of $200 \mathrm{~g}$ and a dwell time of $15 \mathrm{~s}$. Pin-on-disk tribotests were conducted to compare the wear performance of the DI substrate, PTA-alloyed, remelted DI and the known wear-resistant Mn13 tool steel. The dimensions of the sample pins were $6 \mathrm{~mm}$ in diameter and $12 \mathrm{~mm}$ in height. The rotating disk (GCr15 bearing steel, hardness of $60 \pm 1.5 \mathrm{HRC}$ ) with a diameter of $70 \mathrm{~mm}$ was used as the counter-body. All the wear tests were performed with a sliding time of $10 \mathrm{~min}$ at a fixed linear velocity of $0.75 \mathrm{~m} / \mathrm{s}$ and a normal load of $100 \mathrm{~N}, 150$ $\mathrm{N}, 200 \mathrm{~N}, 250 \mathrm{~N}$, respectively. The wear mass loss of the specimens was calculated from the weight change after each test weighed by a METTLER TOLEDO analytical balance with an accuracy of $0.1 \mathrm{mg}$. After the tests, the wear tracks were observed by SEM.

\section{RESULTS AND DISCUSSIONS}

\subsection{Microstructure and composition}

The cross-sectional microstructure of the plasma beam alloyed DI specimen is shown in Fig. 2. Figure 2a indicates that the sample can be divided into three regions: (1) the top alloyed zone (AZ); (2) the intermediate melted zone (MZ); and (3) the heat-affected zone (HAZ). These three distinct zones are formed as the plasma beam simultaneously melts the pre-placed powder and the substrate surface, and the enrichment of alloying elements in the melt pool decreases along the depth direction. The alloying elements are dissolved into a limited depth and form a thin alloying zone of about $200 \mu \mathrm{m}$ thickness. The AZ contains large amount of ultrafine and spherical dark particles that are homogeneously dispersed in the coating, see Fig. 2b. The subsurface remelting of DI
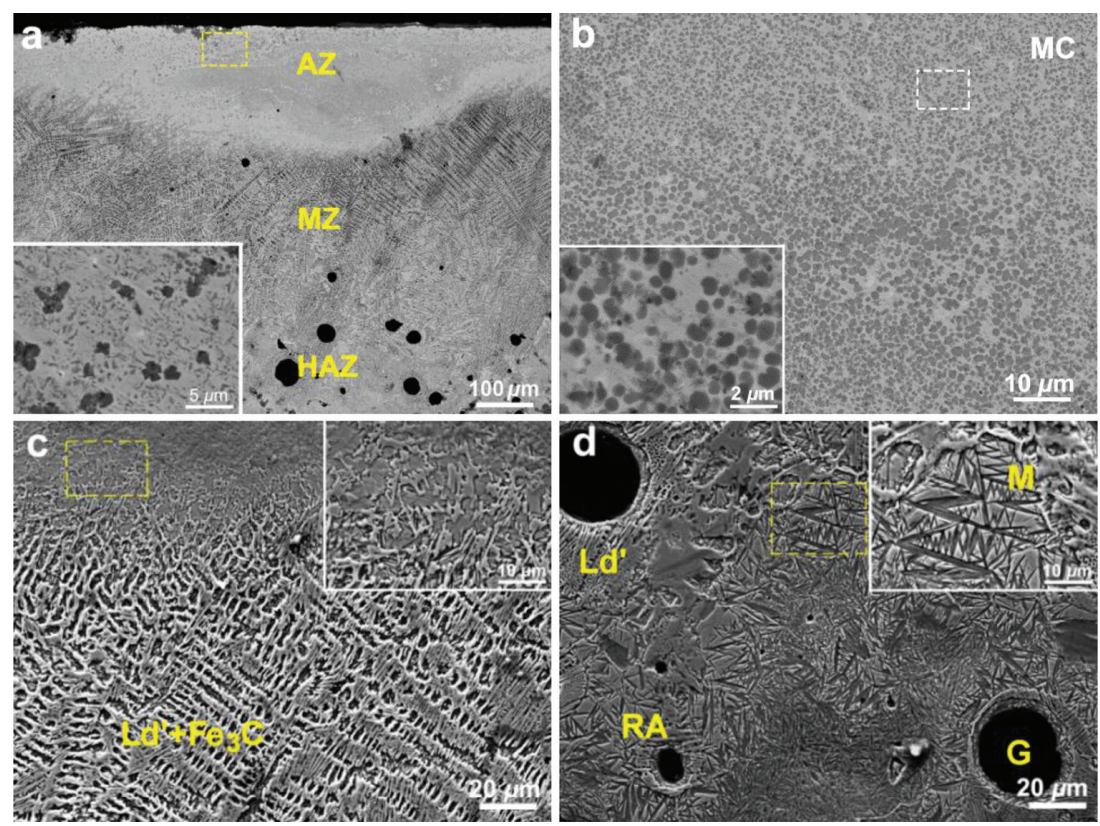

Figure 2: Cross-sectional SEM micrographs: (a) low-magnified overview; (b) the middle section of alloyed zone (AZ); (c) the melted zone (MZ); (d) heat-affected zone (HAZ) (Note 1: the insets are marked high-magnified images; Note 2: Ld'ledeburite; M-martensite; RA-residue austenite; G-graphite). 
substrate results in a structure similar to white cast iron consisting of lathy cementite and interdendritic eutectic ledeburite (Ld'), as shown in Fig. 2c. From the inset image of Fig. 2c, it is seen that the addition of alloy elements fragments the original interconnected ledeburite into segregated crystals, which releases the high stress prevalently existing in the cellular structure [10]. At the bottom MZ (Fig. 1d), reduced plasma energy results in decreased molten time that limits austenite transformation during the solidification and produces a mixture of modified ledeburite surrounding the graphite nodules of dwindled diameters, high carbon twinned martensite (Z-shaped grains) and residual austenite (bitty areas segregated by martensite). Substantial martensite results in high hardness and strength in steels, which makes the MZ/ HAZ transition zone to some extent hard and brittle [11].

To estimate the size and density of MC particles formed in AZ, Fig. 2b was analyzed with software ImageJ. It is found that the volume fraction of MC could reach 51\% and the average diameter of granular MCs is around $0.75 \mu \mathrm{m}$ (see Fig. 3). Due to the large composition and temperature gradient in the melt pool, the carbides in the upper alloyed layer where the longer time above the liquidus was retained due to higher energy adjacent to the outward surface evolve from spheroidal to polyhedral and even flower-like, the size of carbides particles still ranges from submicron to below $5 \mu \mathrm{m}$. Another reason for the relatively larger crystals in the upper $\mathrm{AZ}$ is because the hydrodynamic forces or convection induced by the turbulent argon flow acting on the molten pool bring about distribution dissimilarity of alloy elements. The particles consequently gain greater probability to collide and assemble into bigger aggregates. However, stable and hard MCs can restrain boundary movement and inhibit grains from free coarsening [10]. Higher cooling rate leads to shorter solidification and larger undercooling yields finer microstructure correspondingly [12]. The characteristics of extremely high cooling and solidification rate during PTA process prevent the carbides from growing freely to form coarse grains and thus account for the formation of dense and refined carbides and matrix microstructure.

The micro-sized particles in AZ are determined as MC-type carbides, especially VC considering the high concentration of $\mathrm{V}$ as confirmed by the EDS shown in Fig. 4. Figure $4 \mathrm{a}$ and $\mathrm{b}$ show dark particles being V-rich phases, partly doped with a bit of Ti (see the inset in Fig. 4a), elucidating that the fine VC-TiC crystals tend to grow together to form double carbide [13]. This is because VC and TiC carbides share a NaCl-type face centred cubic (FCC) structure with a small crystal lattice mismatch $\left(a_{V C}=0.417 \mathrm{~nm}, a_{T i C}=0.432 \mathrm{~nm}\right)$ and thus have good mutual compatibility [14-16]. Wang et al. [14] reported that VC-TiC system fulfils the Hume-Rothery
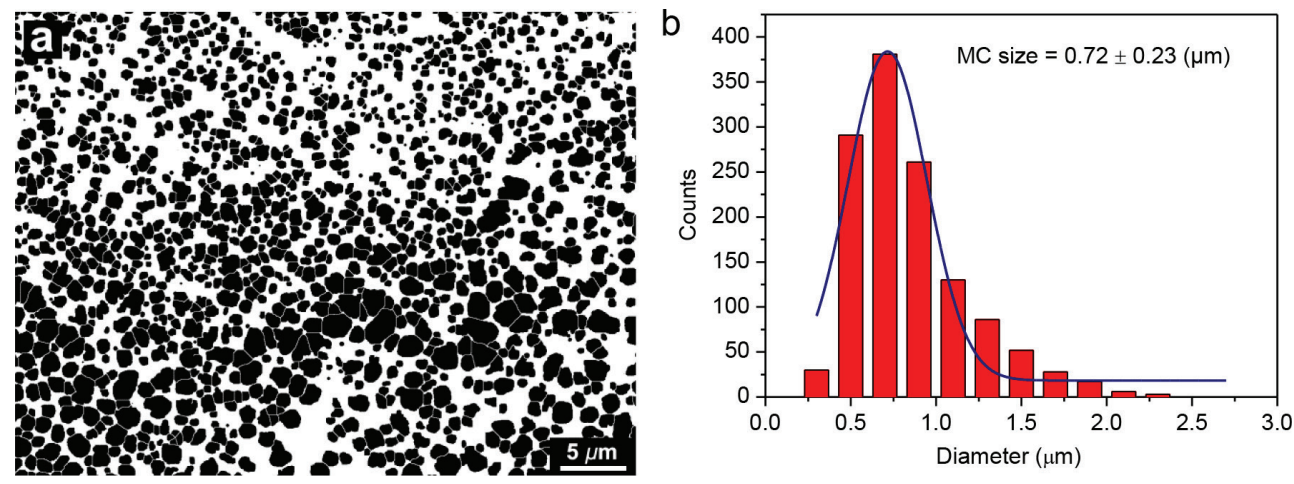

Figure 3: MC micro-particles analyzed by ImageJ software; (b) statistical distribution of MC diameters. 

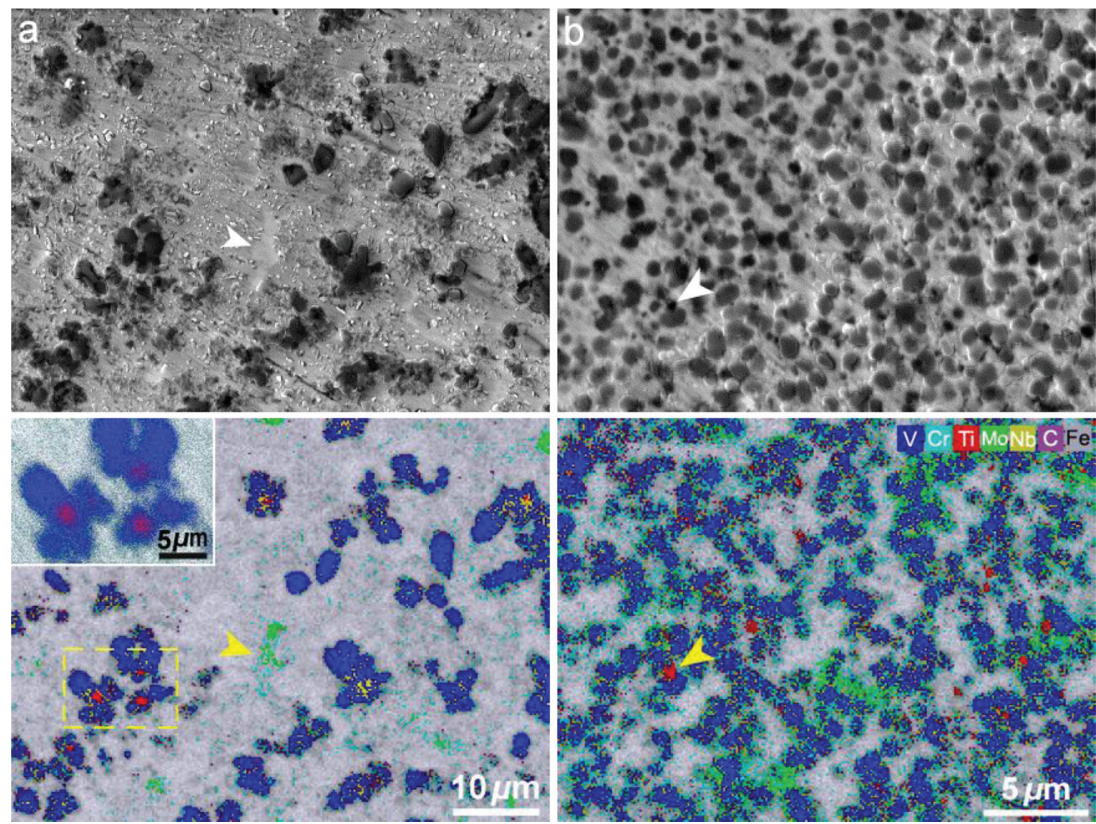

Figure 4: Secondary electron SEM images with corresponding overlaid EDS mappings in two different areas of HVHSS layer: (a) the top AZ; (b) the middle AZ.

condition, which means that metallic atoms can be substituted or moved without impairing the FCC structure stability such that they can randomly distribute inside the solid solution. Still, it is important to highlight that $\mathrm{VC}$ has superior wetting ability to iron than $\mathrm{TiC}$, which renders it more easily being engulfed by the liquid-solid interface front and then dispersed homogeneously in the alloy matrix. EDS mapping in Fig. 4 also indicates that the elements of $\mathrm{V}, \mathrm{Ti}$ and $\mathrm{Nb}$ are prone to enrich in the MC particles instead of in the matrix as solid solution. The large whitish platelet shown by an arrow in Fig. 4a supposes to be a $\mathrm{M}_{2} \mathrm{C}$-type carbide containing molybdenum $\left(\mathrm{Mo}_{2} \mathrm{C}\right)$. Cr carbides are found to grow along $\mathrm{MC}$ carbides as indicated in Fig. $4 \mathrm{~b}$. It is noteworthy that the Ti-, Mo-, $\mathrm{Cr}$ - and $\mathrm{Nb}$-containing carbides are much smaller than the primary VC particles, making it difficult to characterize their phase structure. Apart from the relatively larger primary carbides, the remaining liquid reaches the eutectic composition at the grain boundaries. As a result, rod-like MC eutectic carbides (see the inset in Fig. 2a) are distributed along network boundaries after eutectic transformation [9].

\subsection{Phase structure}

The XRD spectra of DI substrate and plasma alloyed layer are shown in Fig. 5. For the untreated DI, only diffraction peaks of $\alpha$-Fe and graphite can be indexed (Fig. 5a). Several carbides phases formed in the alloyed layer are identified as $\mathrm{MC}$ and $\mathrm{M}_{2} \mathrm{C}(\mathrm{M}=\mathrm{V}, \mathrm{Ti}, \mathrm{Nb}$ and $\mathrm{Mo}$ ) type carbides. It should be noted that $\mathrm{Cr}$ in the melt favors the formation of chromium carbides rather than $\mathrm{Fe}_{3} \mathrm{C}$ because $\mathrm{Cr}$ has a stronger affinity to form carbides than iron [17]. Besides, the high cooling rate in PTA process increases the solubility of alloy elements in the matrix [5], thereby rendering superfluous alloy to form carbide solid solutions [18] such as $\mathrm{Mo}_{2} \mathrm{~V}_{4} \mathrm{C}_{5}$ and $\mathrm{Ti}_{0.42} \mathrm{~V}_{1.58} \mathrm{C}$. It is noteworthy that martensite and retained austenite were also detected. 


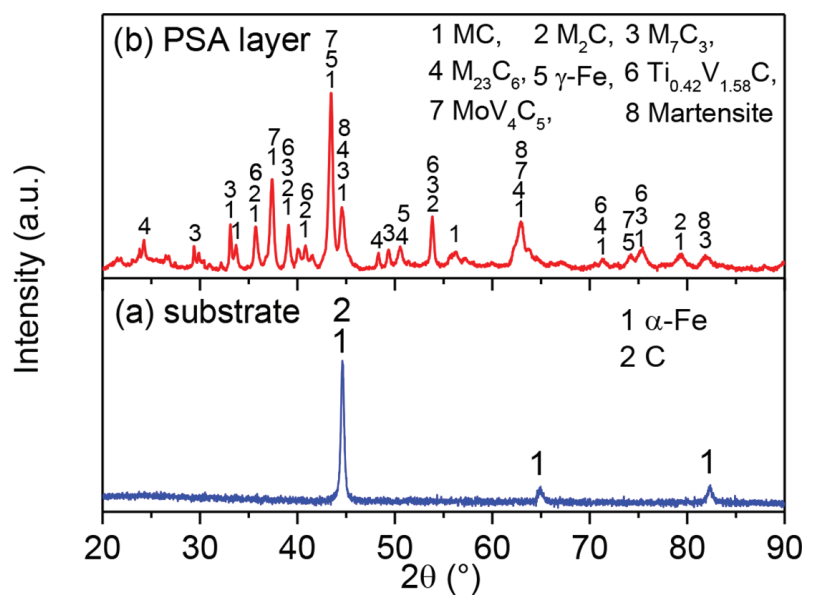

Figure 5: XRD spectra of (a) bare iron substrate and (b) plasma alloyed layer.

Along with XRD analysis, TEM was further employed to identify VC. Figure 6a shows the ellipsoidal, or lumpy carbides embedded in the coating. The EDS spectra (see Fig. 6b) indicate that \#1 region can be identified as V-rich phases while \#2 region is iron rich. The selected area diffraction pattern (Fig. 6c) and HRTEM micrograph (Fig. 6d) ascertain \#1 particle is VC (JCPDS No. 065-7885), as often observed in [4, 15, 19]. It is worth mentioning that EDS
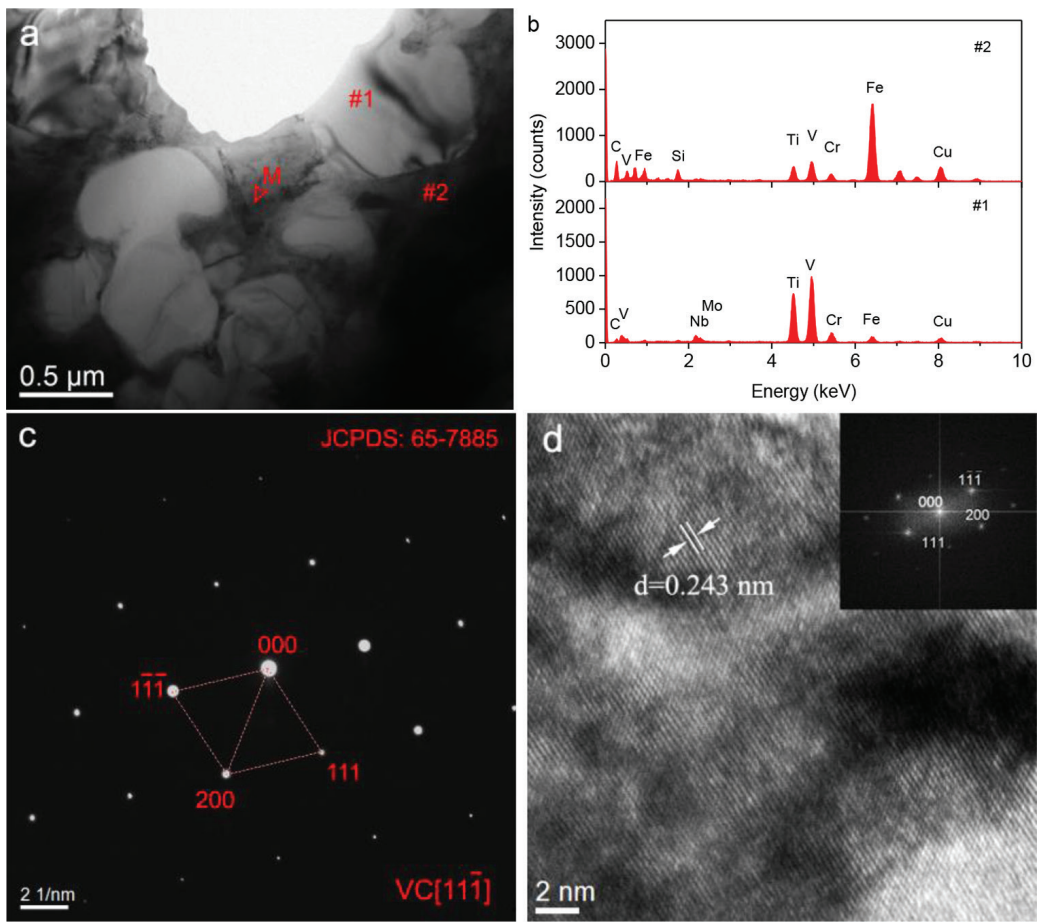

Figure 6: (a) TEM images showing alloy carbides (M refers to martensite); (b) EDS analysis of area \#1 and area \#2; (c) Diffraction pattern of area \#1 confirming VC cystal with $[11 \overline{1}]$ zone axis; (d) HRTEM image of VC in area \#1 with the inset of reversed FFT. 
\#1 reveals a relatively high amount of $\mathrm{Ti}$, which indicates possible formation of $(\mathrm{V}, \mathrm{Ti}) \mathrm{C}$. Figure 6a also exhibits twined martensite formed in the matrix between carbides.

\subsection{Microhardness and wear properties}

Figure 7 shows the microhardness profile of the PTA-alloyed sample across the depth. It can be seen that the microhardness of the AZ in HVHSS alloyed sample reaches a maximum value of $950 \mathrm{HV}_{0.2}$ near the surface of the zone, which is nearly five times as high as that of the substrate. Therefrom, the microhardness gradually decreases from about $820 \mathrm{HV}_{0.2}$ to $630 \mathrm{HV}_{0.2}$ in the RZ and then further decreases in the HAZ to the initial hardness of the substrate, approximately $200 \mathrm{HV}_{0.2}$. The enhanced hardness is attributed to both the synergistic effects of hard alloy precipitates strengthening and solid solution hardening as well as fine-grain strengthening.

The weight loss of the samples of PTA-alloyed, PTA-remelted, standard Mn13 steel and DI substrate, respectively, under dry sliding tests are illustrated in Fig. 8. The PTA-alloyed and

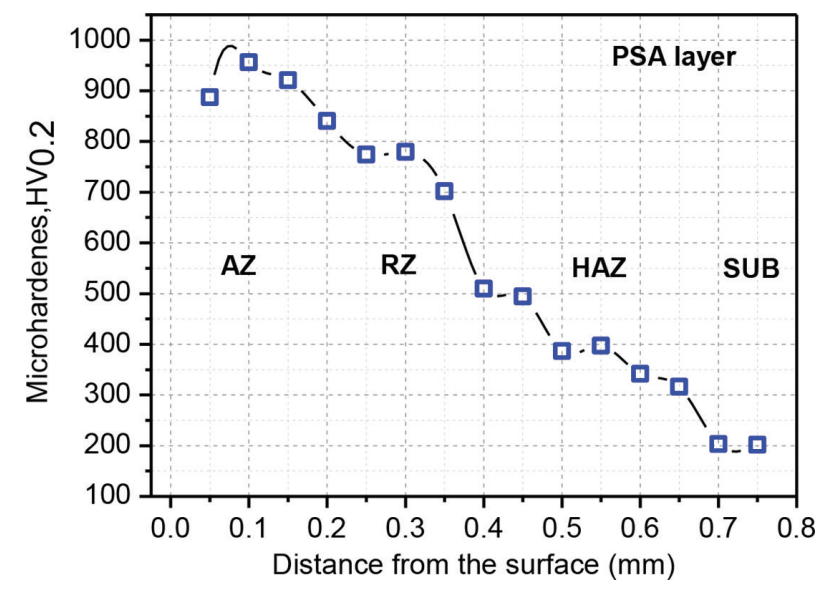

Figure 7: Microhardness profile of PTA alloyed layer as a function of the depth.

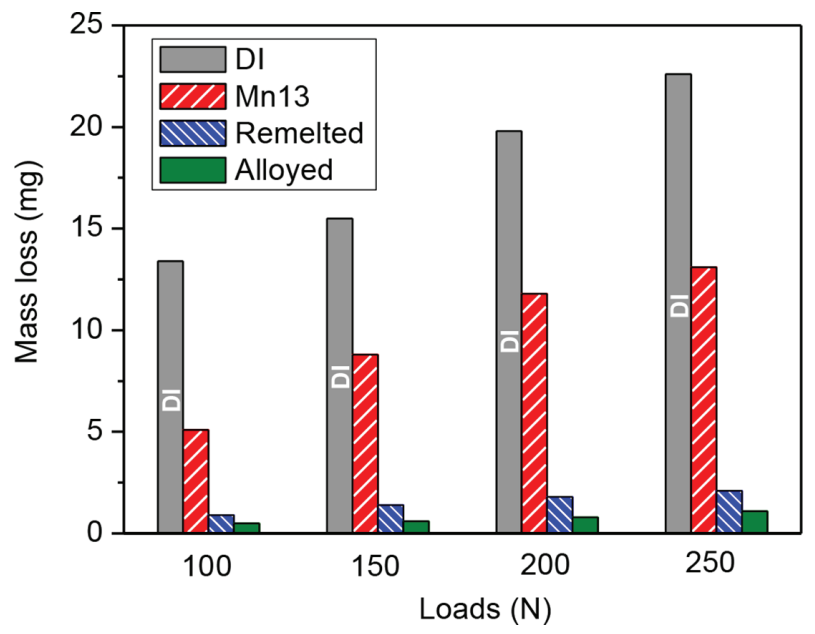

Figure 8: Wear loss of four different samples as a function of normal load after dry sliding for $10 \mathrm{~min}$. 
remelted samples show minor changes in terms of weight loss within the entire range of the normal load from $100 \mathrm{~N}$ to $250 \mathrm{~N}$. Especially, the PTA-alloyed sample loses only $0.4 \mathrm{mg}$ to 1.1 mg with increasing the normal load from $100 \mathrm{~N}$ to $250 \mathrm{~N}$, and the wear loss of the PTA-remelted sample is $0.9 \mathrm{mg}$ to $2.1 \mathrm{mg}$. In contrast, the DI has suffered the greatest weight loss from $13.4 \mathrm{mg}$ to $22.6 \mathrm{mg}$ correspondingly, which are over 20 times higher than the weight loss of the PTAalloyed samples. As can be seen, the Mn13 sample is still inferior to the PTA-treated samples whether by alloying or remelting in terms of wear resistance to mass removal.

Further details can be deduced from the worn surfaces revealed in Fig. 9. The PTA-alloyed sample has an extremely smooth and compact morphology with only slight scratches, suggesting that the HVHSS layer is inherently hard-yet-tough. This is primarily attributed to the large amount of reinforcing carbides particles $\left(\mathrm{MC}, \mathrm{M}_{7} \mathrm{C}_{3}, \mathrm{M}_{23} \mathrm{C}_{6}\right)$ that act as obstacle against abrasive and adhesive wear as shown in Fig. 9a. Figure 9a obviously indicates that several tiny and shallow scratches stop due to the strong wear resistance of hard carbides. Another contributing factor is that the refined globular particles may lead to low brittleness and suppress crack propagations. The mechanism is elucidated in elsewhere [10]. Furthermore, the hard RZ, as a buffer layer at the subsurface of AZ, can assist the AZ to bear higher loads and thus protect the substrate from heavy wear by wear mechanisms like fragmentation or micro-fracturing. While the worn surface of PTA-remelted sample is relatively smooth with plastic deformation features as a result of enhanced hardness due to the formation of cementite and ledeburite, the formed craters (see Fig. 9b) suggest that the plate-like cementite and cellular ledeburite reinforced hard layer is brittle and more susceptible to spalling and cracking. As for the Mn13 steel sample comprised of single austenite, although having excellent toughness, the lack of hard reinforcement and the insufficiently high sliding pressure to trigger work-hardening make it powerless to resist the shear forces from the counterpart [20]. This explains why some micro-cutting and severe adhesive wear characteristics are observed in Fig. 9c. A comparison of the PTA-modified samples and untreated substrate reveals that the wear surface of DI substrate exhibits loose rippled surface topography and serious ploughing grooves. The deep pits and wide furrows formed on the wear surface illustrate that large areas of bulk material are worn off owing to its low hardness because the DI consists mainly of soft ferrite and graphite.

Figure 10a shows the cross-section schematic graph of the graded material model for the PTA-alloyed HVHSS coating on a DI substrate. Figure 10b and c compare the crack-free
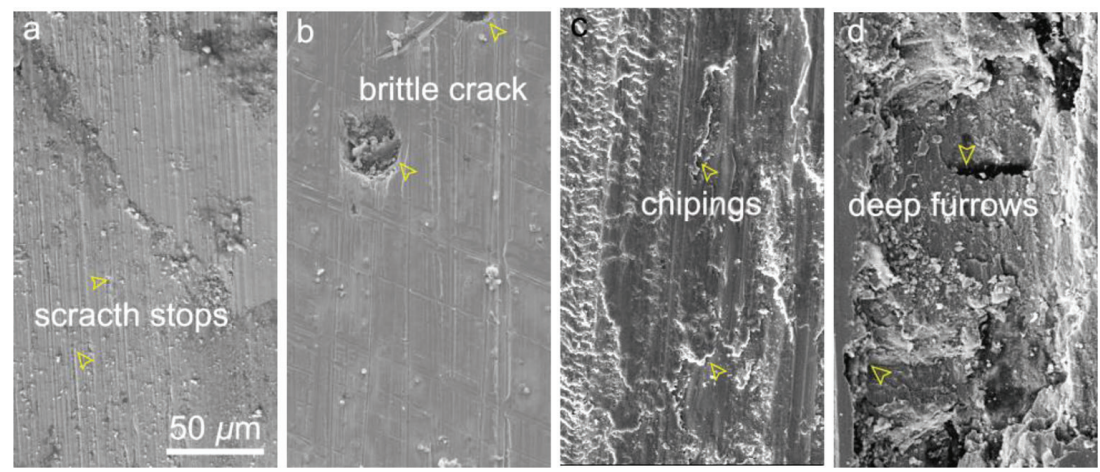

Figure 9: SEM images showing wear morphologies of four different samples under $200 \mathrm{~N}$ : (a) PTA alloyed; (b) PTA remelted DI; (c) Mn13 steel; (d) DI substrate. 

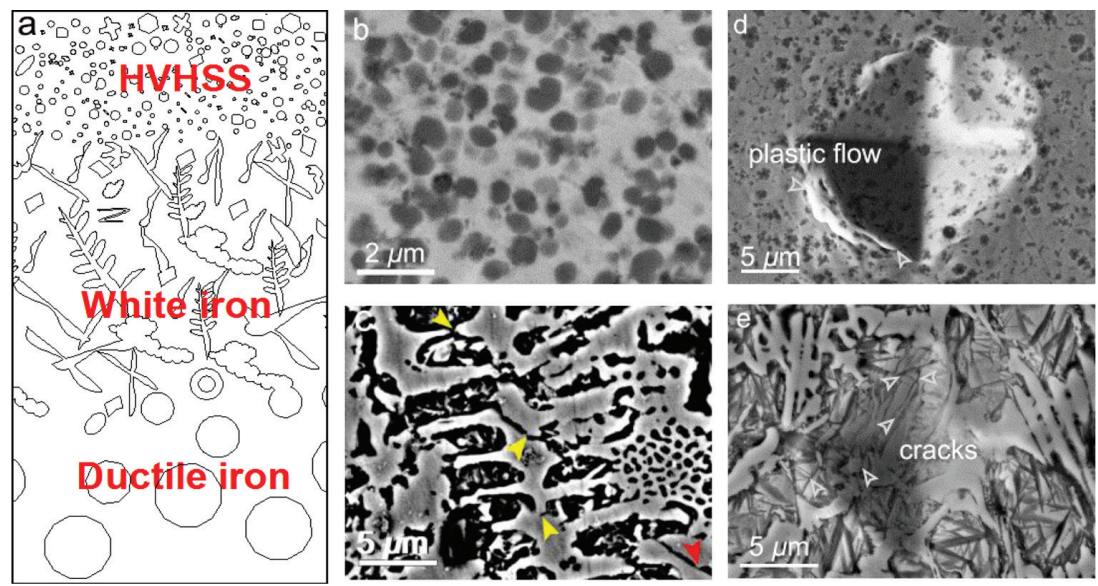

Figure 10: (a) Schematic of graded material model of PTA-alloyed HVHSS; (b) crack-free alloyed MC spherical reinforcement; (c) fracture-induced remelted $\mathrm{M}_{3} \mathrm{C}$ platelike reinforcement; (d) Micro-indentations of ductile-alloyed layer confirmed with plastic deformation; (e) Micro-indentations of brittle remelted layer confirmed with cracks

PTA-alloyed MC spherical reinforcement and the brittle PTA-remelted $\mathrm{M}_{3} \mathrm{C}$ platelike reinforcement with both transcrystalline (yellow arrow) and intergranular (red arrow) fractures. The clear plastic material flow and smooth indenting surface of the alloyed HVHSS (see Fig. 10d) and numerous initialized microcracks of the remelted $\mathrm{M}_{3} \mathrm{C}$ (see Fig. 10e), together with the wear behaviors aforementioned, lead to the conclusion that the dispersed spherical MC-reinforced HVHSS coating of submicro-meter size combines high hardness, high abrasive resistance and adequate toughness.

\section{CONCLUSIONS}

A novel graded coating of MC-particle reinforced HVHSS alloy composites-white iron was directly in-situ fabricated on a DI substrate by plasma surface alloying process.

1. The plasma alloyed layer is featured by spheroidal MC particles of average size $<1 \mu \mathrm{m}$. The melted zone chiefly consists of intercellular ledeburite and cementite, embedded with a large proportion of twined martensite. Ledeburite and martensite double shells are formed at the heated affected zone.

2. Globular MC particles combined with multiple hard phases such as $\mathrm{M}_{2} \mathrm{C}, \mathrm{M}_{7} \mathrm{C}_{3}, \mathrm{M}_{23} \mathrm{C}_{6}$ and martensite dispersed in a ledeburite and or austenite matrix make the PTA-alloyed HVHSS material hard-yet-tough, less susceptible to cracking compared with lathy cementite dominated white iron obtained by PTA remelting. Micro-indentations verify the preferred plasticity.

3. Wear tests indicate excellent tribological performance of the PTA alloyed HVHSS layer. The hard carbides particles act as obstacle against abrasion and adhesive wear. The PTAalloyed HVHSS layer provides a superior solution for enhancing the wear resistance of DI. 


\section{ACKNOWLEDGMENTS}

The PTA surface treated ductile iron specimens were made at Huazhong University of Science and Technology, China. Huatang Cao acknowledges financial support from China Scholarship Council.

\section{REFERENCES}

[1] Abboud, J.H., Microstructure and erosion characteristic of nodular cast iron surface modified by tungsten inert gas. Materials \& Design, 35, pp. 677-684, 2012.

https://doi.org/10.1016/j.matdes.2011.09.029

[2] Shamanian, M., Abarghouie, S.M.R.M. \& Pour, S.R.M., Effects of surface alloying on microstructure and wear behavior of ductile iron. Materials \& Design, 31, pp. 2760 2766, 2010.

https://doi.org/10.1016/j.matdes.2010.01.017

[3] Cao, H.T., Dong, X.P., Huang, Q.W., Pan, Z., Li, J.J. \& Fan, Z.T., Effect of scanning speed during PTA remelting treatment on the microstructure and wear resistance of nodular cast iron. International Journal of Minerals, Metallurgy, and Materials, 21, pp. 363-370, 2014. https://doi.org/10.1007/s12613-014-0917-6

[4] Godec, M., Batič, B.Š., Mandrino, D., Nagode, A., Leskovšek, V., Škapin, S.D. \& Jenko, M., Characterization of the carbides and the martensite phase in powdermetallurgy high-speed steel. Materials Characterization, 61, pp. 452-458, 2010. https://doi.org/10.1016/j.matchar.2010.02.003

[5] Bourithis, L. \& Papadimitriou, G.D., Synthesizing a class "M" high speed steel on the surface of a plain steel using the plasma transferred arc (PTA) alloying technique: microstructure and wear properties. Materials Science and Engineering: A, 361, pp. 165-172, 2003. https://doi.org/10.1016/s0921-5093(03)00511-2

[6] Hwang, K.C., Lee, S. \& Lee, H.C., Effects of alloying elements on microstructure and fracture properties of cast high speed steel rolls: Part I: microstructural analysis. Materials Science and Engineering: A, 254, pp. 282-295, 1998. https://doi.org/10.1016/s0921-5093(98)00626-1

[7] Navas, C., Conde, A., Fernández, B.J., Zubiri, F. \& de Damborenea, J., Laser coatings to improve wear resistance of mould steel. Surface and Coatings Technology, 194, pp. 136-142, 2005.

https://doi.org/10.1016/j.surfcoat.2004.05.002

[8] Sun, G.F., Wang, K., Zhou, R., Feng, A.X. \& Zhang, W., Effect of different heat-treatment temperatures on the laser cladded M3:2 high-speed steel. Materials \& Design, 65, pp. 606-616, 2015. https://doi.org/10.1016/j.matdes.2014.09.058

[9] Davis, J.R. ed., Cast iron. ASM International, Materials Park, OH, 1996.

[10] Cao, H.T., Dong, X.P., Pan, Z., Wu, X.W., Huang, Q.W. \& Pei, Y.T., Surface alloying of high-vanadium high-speed steel on ductile iron using plasma transferred arc alloying technique: microstructure and wear properties. Materials \& Design, 100, pp. 223-234, 2016. https://doi.org/10.1016/j.matdes.2016.03.114 
[11] Hwang, K.C., Lee, S. \& Lee, H.C., Effects of alloying elements on microstructure and fracture properties of cast high speed steel rolls: Part II. fracture behavior. Materials Science and Engineering: A, 254, pp. 296-304, 1998.

https://doi.org/10.1016/s0921-5093(98)00694-7

[12] Zeng, D.W., Xie, C.S. \&Yung, K.C., Mesostructured composite coating on SAE 1045 carbon steel synthesized in situ by laser surface alloying. Materials Letters, 56, pp. 680-684, 2002. https://doi.org/10.1016/s0167-577x(02)00578-5

[13] Arenas, F., Rondón, C. \& Sepúlveda, R., Friction and tribological behavior of (Ti, V) C-Co cermets. Journal of Materials Processing Technology, 143-144, pp. 822-826, 2003.

https://doi.org/10.1016/s0924-0136(03)00340-6

[14] Jing, W., Yisan, W. \& Yichao, D., Reaction synthesis of Fe-(Ti,V)C composites. Journal of Materials Processing Technology, 197, pp. 54-58, 2008. https://doi.org/10.1016/j.jmatprotec.2007.06.016

[15] Wang, X.-H., Han, F., Qu, S.-Y. \& Zou, Z.-D., Microstructure of the Fe-based hardfacing layers reinforced by TiC-VC- $\mathrm{Mo}_{2} \mathrm{C}$ particles. Surface and Coatings Technology, 202, pp. 1502-1509, 2008.

https://doi.org/10.1016/j.surfcoat.2007.07.002

[16] Dong, X.-C., Yue, J.-1., Wang, E.-q., Li, M.-1. \& Li, G.-Y., Microstructure and superhardness effect of VC/TiC superlattice films. Transactions of Nonferrous Metals Society of China, 25, pp. 2581-2586, 2015. https://doi.org/10.1016/s1003-6326(15)63878-X

[17] Tong, X., Dai, M.-J. \& Zhang, Z.-H., Thermal fatigue resistance of H13 steel treated by selective laser surface melting and CrNi alloying. Applied Surface Science, 271, pp. 373-380, 2013. https://doi.org/10.1016/j.apsusc.2013.01.209

[18] Zhang, H., Zou, Y., Zou, Z. \& Wu, D., Microstructure and properties of Fe-based composite coating by laser cladding $\mathrm{Fe}-\mathrm{Ti}-\mathrm{V}-\mathrm{Cr}-\mathrm{C}-\mathrm{CeO}_{2}$ powder. Optics \& Laser Technology, 65, pp. 119-125, 2015. https://doi.org/10.1016/j.optlastec.2014.06.016

[19] Yan, F., Xu, Z., Shi, H. \& Fan, J., Microstructure of the spray formed Vanadis 4 steel and its ultrafine structure. Materials Characterization, 59, pp. 592-597, 2008. https://doi.org/10.1016/j.matchar.2007.04.019

[20] Abbasi, M., Kheirandish, S., Kharrazi, Y. \& Hejazi, J., On the comparison of the abrasive wear behavior of aluminum alloyed and standard Hadfield steels. Wear, 268, pp. 202-207, 2010.

https://doi.org/10.1016/j.wear.2009.07.010 